Article

\title{
Cloud-Based Virtual Port-Container Terminal Establishment and Operation Analysis
}

\author{
Gyusung Cho ${ }^{1, * \mathbb{D}}$ and Suk-Hwan Lee ${ }^{2}$ \\ 1 Department of Port Logistics System, Tongmyong University, 428, Sinseon-ro, Nam-gu, Busan 48520, Korea \\ 2 Department of Computer Engineering, Dong-A University, 37, Nakdong-daero550beon-gil, Saha-gu, \\ Busan 49315, Korea; skylee@dau.ac.kr \\ * Correspondence: gscho@tu.ac.kr; Tel.: +82-51-629-1466
}

Received: 17 August 2020; Accepted: 25 September 2020; Published: 1 October 2020

\begin{abstract}
Worldwide, governments are making efforts to enhance the efficiency of port terminals by applying new technologies developed in the context of the Fourth Industrial Revolution. This study aims to systematically analyze port productivity and operational efficiency by establishing cloud-based virtual port-container terminals using operational data from Busan Port terminals. Accordingly, the integrated aspect-oriented modeling approach is applied to actual operational data from port-container terminals to develop a reusable, extendible and modifiable control system. This technique is used to establish a virtualized port-container terminal. In addition, this study presents a way to solve various problems arising from port-container terminals by analyzing real-time operation data generated by the terminals through a cloud system, as well as suggests ways to streamline operations. The methodology presented in this study can be applied to establish optimal operating systems for various ports and to develop and operate future port-container terminal systems.
\end{abstract}

Keywords: virtual port-container terminal; cloud system; integrated aspect-oriented modeling approach; logistics system; system design and operation

\section{Introduction}

Given the worldwide increase in port flow rates and the emergence of high-potential markets such as China, the flow rate of processed waste in the Northeast Asian region has increased significantly [1]. Additionally, the carrying capacity of ships has continued to grow. As a result, systematic planning and operation of port facilities in each country are essential for the efficient treatment of material flows. Efforts to increase productivity and efficiency include the automation of cargo-handling systems at port-container terminals, enhancement of operation systems, relocation of container terminal facilities and retraining of operators. To enhance the economic effect of port operations, it is also important to continuously pursue business improvements that can make container terminals more competitive. A competitive container terminal offers a high level of service that expedites the import/export of cargo, thus allowing ships to spend less time at ports [2].

To streamline the operations of container terminals, Kang et al. [3] developed a dedicated simulator to calculate terminal capacity by applying dynamic systems theory. This led to an object-oriented operation simulation. Scholars have also suggested using simulation models to develop field devices for automated container terminals or evaluate the capacity of port-container terminal operations $[4,5]$.

Most research on the operation of existing port-container terminals has been conducted using simulations. However, as these simulation techniques are object-oriented, their ability to reflect the various operating environments of port-container terminals is limited. Hence, simulation methods using aspect-oriented techniques are required to complement the literature [6-8]. 
Since the advent of the Fourth Industrial Revolution in the 2000s, there have been rapid developments in information and communications technologies (ICT), such as the cloud, the Internet of things (IoT), big data, and artificial intelligence (AI). ICT is fundamentally changing industries, and port-container terminals are no exception. Furthermore, countries must improve their logistics systems to operate port facilities efficiently. Advanced ports worldwide can be made more efficient through the use of technologies such as AI, IoT, autonomous driving and the cloud. In the era of the Fourth Industrial Revolution, the role of traditional shipping and port logistics will be weakened, and the global supply chain will change markedly because of ICT convergence [9].

Previously, securing ships, shippers and supplies was a competitive process, but as oversupply and recessions continue, survival strategies have become necessary. Virtualization is a strategy that provides cost, time and convenience advantages. This is because computer resources are used to provide services while minimizing the use of physical resources [10]. Additionally, the importance of cloud applications for port-container terminals has already been demonstrated as the technology is currently being applied to check the dynamic location of container cargo within a terminal in real time [11].

South Korea's Busan Port is the world's sixth-largest port-container terminal in terms of volume. That is, it handles around 75 percent of the country's offshore container traffic. South Korea has begun constructing smart "4.0-based" ports to reduce the pressure on Busan Port, but these are insufficient [12]. Therefore, this study presents a plan to secure the competitiveness of the port-container terminal at Busan Port by establishing a cloud-based virtualized container terminal [13]. We propose cloud-based virtualization because the data currently used in operating the port-container terminals are built on the cloud. To analyze the efficient operation of the port-container terminal, it is necessary to implement it virtually based on cloud data. Specifically, we build our cloud-based virtualized port-container terminal using integrated aspect-oriented modeling approach (i-AOMA) techniques, which link object- and aspect-oriented simulation techniques. Additionally, we propose measures to improve port-container terminals and reduce operating costs by calculating total container throughput and operating equipment working hours. This method uses the example of virtualized port-container terminals implemented based on the actual operational data of port-container terminal " $\mathrm{A}$ ".

\section{Port-Container Terminal Operation Capacity}

A port-container terminal is a hub for the arrival and departure of import and export cargo. Its operational capacity is the volume of containers it can load and unload at any given time, which is closely related to the number of berths and cargo-handling equipment it has. The loading capacity is the size of the berth that can accommodate an arriving vessel and the quantity of cargo that can be loaded or unloaded, depending on the size and productivity of the loading and unloading equipment. A port-container terminal's appropriate loading and unloading capabilities are simultaneously considered [2,14].

Scholars have presented various methods for determining the loading and unloading capabilities of port-container terminals. In this study, however, the loading and unloading capabilities depend largely on internal and external factors. External factors refer to the loading and unloading abilities of port users (e.g., shipping companies), which can provide externally competitive services. Internal factors refer to the minimum processing capacity needed to achieve the target rate of return. This study approaches the operation plan of a port-container terminal by considering the effects of various operating environments in increasing the profits of enterprises.

\section{Materials and Methods}

\section{1. $i-A O M A$}

AOMA consists of a primary model and at least one sub-model and can be used to demonstrate programmatic mechanisms for expressing crosscutting concerns. It is an analytic approach that 
combines aspect-oriented modeling with existing object-oriented modeling, while acknowledging crosscutting concerns.

In this study, the i-AOMA is based on aspect-oriented programming, which makes it possible to express programs, including appropriate isolation, composition and the reuse of aspect code (Figure 1) [6]. The i-AOMA is built on a conceptual framework and is used to denote the space of modeling elements for specifying crosscutting concerns at a higher abstraction level [7].

\begin{tabular}{|c|c|c|c|}
\hline \multicolumn{4}{|c|}{$\begin{array}{c}\text { integrated Aspect-Oriented Modeling } \\
\text { Approach(i-AOMA) }\end{array}$} \\
\hline \multicolumn{2}{|c|}{ Object-oriented approach modeling(O-O) } & \multicolumn{2}{|c|}{ Aspect-oriented approach modeling(A-O) } \\
\hline & & & \\
\hline Conveyors system & Machines \& workers system & \multicolumn{2}{|c|}{ Process system } \\
\hline \multicolumn{2}{|c|}{ Cross cutting concern } & \multirow{2}{*}{\multicolumn{2}{|c|}{$\begin{array}{l}\text { - Process } \\
\text { - Default traffic limit } \\
\text { - Arriving procedure } \\
\text { - Leaving procedure } \\
\text { - Generation limit } \\
\text { - First one at } \\
\text { - Processing time } \\
\text { - Default capacity } \\
\text { - Initial value } \\
\text { - Parameters } \\
\text { - Bin width }\end{array}$}} \\
\hline $\begin{array}{l}\text { - Load attachment } \\
\text { - Section velocity } \\
\text { - Section acceleration } \\
\text { - Stopping space } \\
\text { - Fixed interval size } \\
\text { - Align load } \\
\text { - Capacity } \\
\text { - Navigation factor } \\
\text { - Station capacity }\end{array}$ & $\begin{array}{l}\text { - Resource cycles } \\
\text { - Pick state set } \\
\text { - Report } \\
\text { - Default transformation } \\
\text { - Use for time } \\
\text { - Set down time } \\
\text { - Break down } \\
\text { - MTTF distribution } \\
\text { - MTTR distribution }\end{array}$ & & \\
\hline
\end{tabular}

Figure 1. Concept of integrated aspect-oriented modeling approach (i-AOMA).

This research suggests a method for analyzing the performance of a cloud-based port-container terminal using i-AOMA. This new methodology can be used to develop reusable, extendible and modifiable control software.

\subsection{Construction of a Cloud-Based Port-Container Terminal}

The cloud comprises the architecture of clients and servers, where client programs are installed on IoT devices to provide user data to applications. It also transfers data copies to remote cloud servers. The cloud serves as a form of storage that allows data to be simultaneously retrieved from multiple locations, not just a single workstation. It is available wherever the Internet is available, thus saving time and money [15].

Cloud technology continues to gain popularity worldwide. The main advantage of using the cloud is the ability to share files on data servers, making them available to multiple users without creating separate instances. Therefore, a cloud-based port-container terminal operating system enables the processing and sharing of real-time information. Similarly, the Busan Port-container terminal operation system is simultaneously available to several port users, including the terminal operation system (TOS), port-maritime information system (Port-MIS), customs and other stakeholders, thereby improving the efficiency of port-container terminal operations. Additionally, improved port operations, such as waiting time for ships, equipment placement and vehicle distribution, were achieved within the port-container terminal by storing actual processed information in the cloud through a combination of cloud and big data.

The cloud-based virtualized port-container terminal considered in this study can be built using actual port data. The simulation methodology used for virtualization increases the efficiency of the analysis and enables operational cost savings. Therefore, the virtualization of cloud-based port-container terminals can be implemented at the actual port and various improvements in operations can be made. Additionally, alternative suggestions can be tested through simulation analysis. This method has the advantage of being able to carry out a series of processes, from planning new ports to construction and operations. 


\section{Results and Discussion}

\subsection{Construction of the Virtualized Port-Container Terminal}

The main purpose of this study is to build and analyze a virtualized port-container terminal using the cloud, one of the technologies of the Fourth Industrial Revolution. Live operational data from the port-container terminal operated at Busan Port were used for simulation using i-AOMA. Table 1 shows the status of the virtualized port-container terminal equipment and operating vessels. A total of five equipment types used in port-container terminals were considered: reach stacker, forklift, yard crane, quay crane and yard tractor. A virtualized port-container terminal was established by considering the working and processing time of each type of equipment.

Table 1. Operation input data for port-container terminal equipment.

\begin{tabular}{cccccc}
\hline Division & Reach Stacker & Forklift & Yard Crane & Quay Crane & Yard Tractor \\
\hline Number of devices (unit) & 8 & 9 & 41 & 15 & 82 \\
Annual total working time (h) & 29,200 & 32,850 & 299,300 & 54,750 & 149,650 \\
Annual total fixed costs (USD) & 80 & 90 & 8300 & 1500 & 420 \\
Total fixed costs per hour (USD) & 10 & 10 & 100 & 36.5 & 356 \\
Total variable costs per hour (USD) & 30 & 30 & 500 & 50 & 500 \\
Maximum number of loading stages & 6 & 6 & 7 & - & \\
Up/down speed(m/s) & - & - & 45 & 45 & - \\
Pick-up time(s) & 10 & 8 & 8 & 30 & 30 \\
Drop-off time(s) & 8 & 8 & 8 & 100 & \\
Hoist speed(m/min) & 23 & 32 & 80 & 30 & \\
Spreader adjustment time (s) & 5 & 5 & 30 & &
\end{tabular}

The schedules of the vessels anchored at the port-container terminal are shown in Table 2. According to the vessel schedule for port " $\mathrm{A}$ " container terminal, the import containers handled by 17 ships totaled 8987 twenty-foot equivalent units (TEUs); the export containers totaled 10,463 TEUs.

Table 2. Vessel schedule of the container terminal in the port.

\begin{tabular}{cccc}
\hline Division & $\begin{array}{c}\text { Arrival Time of the } \\
\text { Ship (h) }\end{array}$ & $\begin{array}{c}\text { Import Container Handling } \\
\text { Volume (TEUs) }\end{array}$ & $\begin{array}{c}\text { Export Container Handling } \\
\text { Volume (TEUs) }\end{array}$ \\
\hline Vessel 1 & $08: 00$ & 497 & 434 \\
Vessel 2 & $10: 00$ & 0 & 1000 \\
Vessel 3 & $17: 00$ & 0 & 58 \\
Vessel 4 & $17: 00$ & 309 & 346 \\
Vessel 5 & $21: 00$ & 118 & 689 \\
Vessel 6 & $26: 00$ & 514 & 172 \\
Vessel 7 & $31: 00$ & 641 & 701 \\
Vessel 8 & $35: 00$ & 712 & 84 \\
Vessel 9 & $42: 00$ & 174 & 1004 \\
Vessel 10 & $46: 00$ & 1252 & 1135 \\
Vessel 11 & $79: 00$ & 358 & 383 \\
Vessel 12 & $79: 00$ & 513 & 296 \\
Vessel 13 & $86: 00$ & 885 & 1412 \\
Vessel 14 & $87: 00$ & 714 & 583 \\
Vessel 15 & $96: 00$ & 1183 & 1119 \\
Vessel 16 & $99: 00$ & 860 & 390 \\
Vessel 17 & $105: 00$ & 257 & 657 \\
\hline
\end{tabular}

\subsection{Analysis of Virtualized Port-Container Terminal}

As previously mentioned, this study aims to analyze the operation of the container terminal by establishing a cloud-based virtualized port-container terminal. A simulation model for quay 
performance analysis is developed as in Figure 2 to determine the performance of this container terminal. This model is based on actual data collected from domestic container terminals, including vessel arrival time distribution, number of assigned quay cranes and crane productivity.

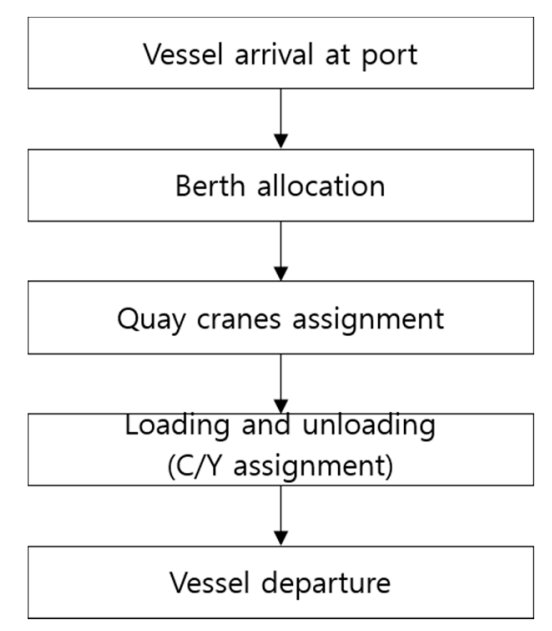

Figure 2. Port-container terminal process.

This simulation model is period-oriented, that is, the system is simulated in constant time intervals (the so-called period length). All activities occurring in the real system in a given interval are correspondingly represented in the model, as shown in Figure 3.

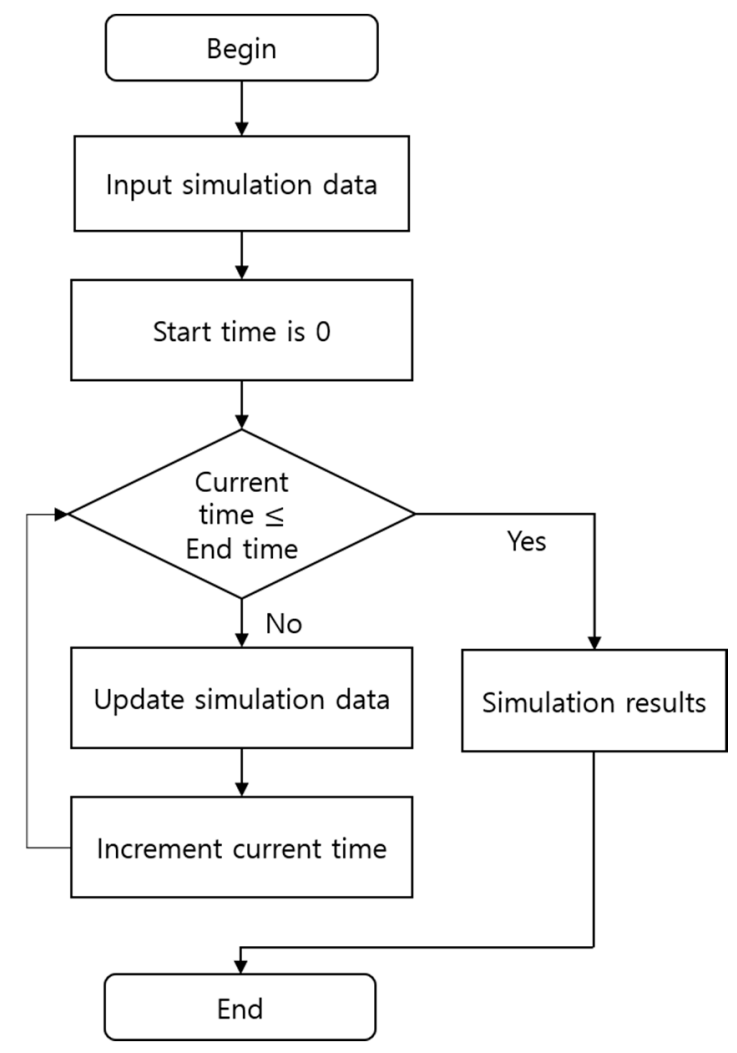

Figure 3. Simulation modeling of virtualized port-container terminal.

In this model, the total area of the port-container terminal is around 1,152,500 $\mathrm{m}^{2}$ and includes five berths; the total length of the inner wall for each berth is $1200 \mathrm{~m}$, with a depth of $16 \mathrm{~m}$. The container unit site has a capacity of around 780,000 TEUs and the freezer unit can store around 1400 TEUs. 
Figure 4 shows the implemented virtual port-container terminal, which is based on the actual Busan port " $\mathrm{A}$ " container terminal. The virtualized port-container terminal consists of a quay, quay crane area, container yard, gate and transfer crane, with a total of 20 blocks.

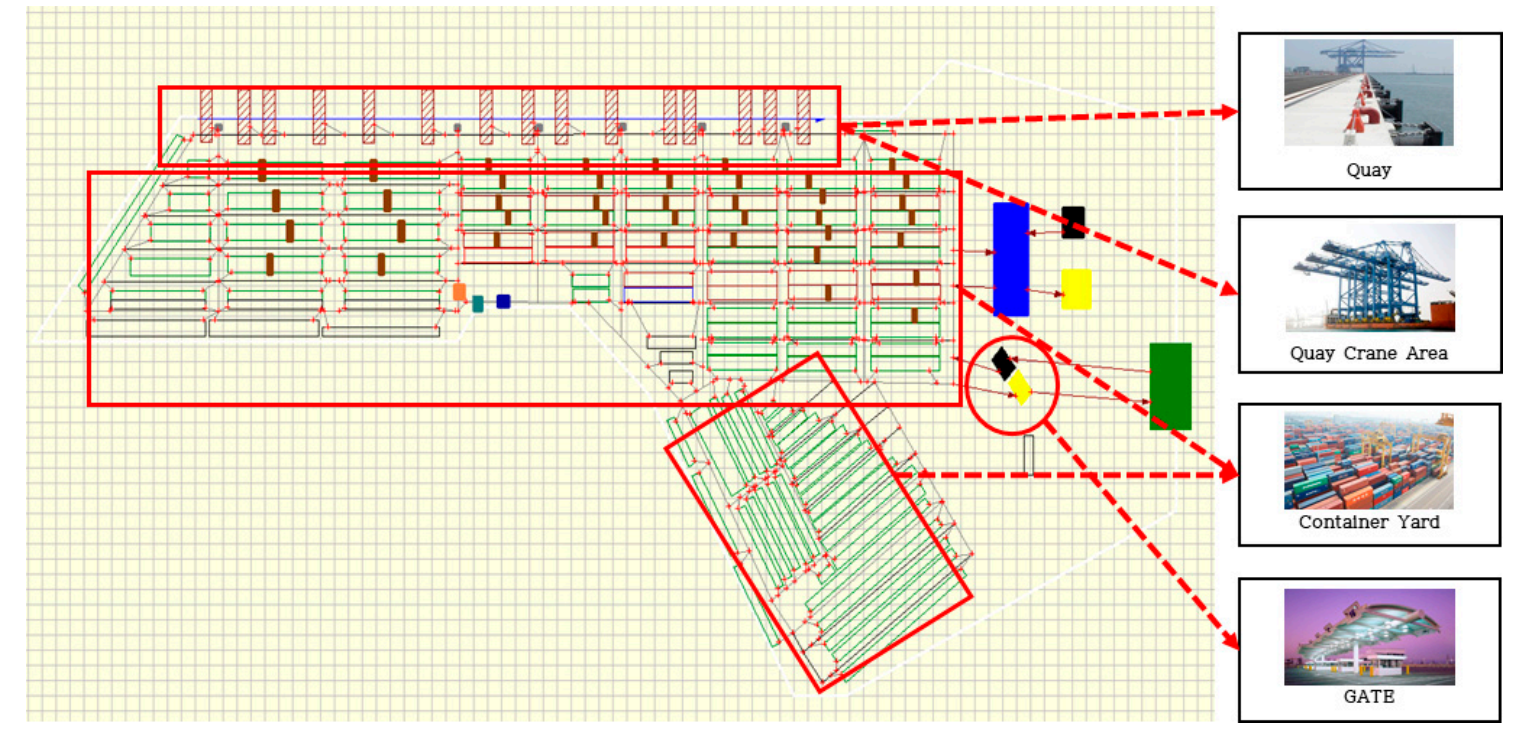

Figure 4. Virtualized port-container terminal.

The implemented virtualized port-container terminal sets the quay crane and the dock location of the vessel according to the mariner. The yard crane is installed and set up in the container equipment cabinet by dividing the containers for import, export, dangerous goods, freezer and empty boxes. Additionally, the path of the operational process for the physical equipment was set from the gate to the yard tractor. The assumptions in this study are that the equipment does not fail during the simulation run time and the ship's landing time is defined in advance, meaning it cannot be changed. Additionally, the number of equipment deployed per vessel is assumed to be constant.

We constructed a container terminal for a virtual port and conducted 10 simulations per year. The computer specifications for building and analyzing the container terminal of the virtual port are OS: Windows 10, Processor: Intel (R) Core (TM) i7-6700 CPU@3.40 GHz, RAM: 8.00 GB, 64-bit system [16].

Table 3 shows the operational results of the reach stacker equipment in the virtualized port-container terminal. Currently, there are eight units of equipment, but the simulation results show that only four units are operational, with a throughput of 1137 TEUs. Therefore, it is more efficient to operate four units of equipment instead of eight at the actual port-container terminal, and the remaining four units can be used as alternatives in case of a failure of the existing reach stacker. Further, no new equipment needs to be introduced. The container throughput is 284 TEUs per reach stacker and 2.37 TEUs/h. The average operating distance per piece of equipment is $43.33 \mathrm{~km}$. The average waiting time at the port-container terminal is $2 \mathrm{~h}$ and $14 \mathrm{~min}$, and the working time is $11 \mathrm{~h}$ and $29 \mathrm{~min}$.

Table 4 shows the operational results of the forklift equipment operating at the virtualized port-container terminal. Among the nine forklifts, the ninth is not operational. Therefore, it is used as an alternative in case of existing equipment failure. Additionally, the average container throughput for the nine forklifts is $271.44 \mathrm{TEUs}$, the moving distance is $11.94 \mathrm{~km}$, and the working time of the forklift equipment is $8 \mathrm{~h}$ and $29 \mathrm{~min}$. However, the waiting time is $10 \mathrm{~h}$ and $29 \mathrm{~min}$. This shows that the waiting time at the port-container terminal is higher than the entire working time of the forklift equipment. Further, the working hours of the eighth forklift are reduced markedly, indicating the actual forklift equipment can be operated with only seven units. 
Table 3. Simulation results of virtualized port-container terminal (reach stacker).

\begin{tabular}{cccccc}
\hline Division & $\begin{array}{c}\text { Container } \\
\text { Throughput (TEU) }\end{array}$ & $\begin{array}{c}\text { Container Throughput } \\
\text { Per Hour (TEU) }\end{array}$ & $\begin{array}{c}\text { Travel } \\
\text { Distance (km) }\end{array}$ & Standby Time (h) & Working Time (h) \\
\hline RS-01 & 0.0 & 0.00 & 0.0 & $0: 00$ & $0: 00$ \\
RS-02 & 0.0 & 0.00 & 0.0 & $0: 00$ & $0: 00$ \\
RS-03 & 0.0 & 0.00 & 0.0 & $0: 00$ & $0: 00$ \\
RS-04 & 0.0 & 0.00 & 0.0 & $1: 43$ & $0: 00$ \\
RS-05 & 153.0 & 1.28 & 15.4 & $2: 20$ & $6: 21$ \\
RS-06 & 208.0 & 1.73 & 21.4 & $2: 22$ & $11: 27$ \\
RS-07 & 292.0 & 2.43 & 44.5 & $2: 34$ & $2: 14$ \\
RS-08 & 484.0 & 4.03 & 42.33 & $2: 18$ \\
Average & 284.25 & 2.37 & & $11: 29$ \\
\hline
\end{tabular}

Table 4. Simulation results of virtualized port-container terminal (forklift).

\begin{tabular}{cccccc}
\hline Division & $\begin{array}{c}\text { Container } \\
\text { Throughput (TEU) }\end{array}$ & $\begin{array}{c}\text { Container Throughput } \\
\text { Per Hour (TEU) }\end{array}$ & $\begin{array}{c}\text { Travel } \\
\text { Distance } \mathbf{( k m )}\end{array}$ & Standby Time (h) & Working Time (h) \\
\hline FL-01 & 807.0 & 6.73 & 15.7 & $28: 17$ & $11: 30$ \\
FL-02 & 496.0 & 4.13 & 14.3 & $25: 16$ & $9: 15$ \\
FL-03 & 296.0 & 2.47 & 12.9 & $12: 41$ & $8: 04$ \\
FL-04 & 225.0 & 1.88 & 14.4 & $6: 26$ & $9: 54$ \\
FL-05 & 212.0 & 1.77 & 15.3 & $4: 13$ & $8: 42$ \\
FL-06 & 189.0 & 1.58 & 16.2 & $3: 12$ & $6: 45$ \\
FL-07 & 151.0 & 1.26 & 12.9 & $2: 53$ & $2: 38$ \\
FL-08 & 67.0 & 0.56 & 5.8 & $0: 53$ & $0: 00$ \\
FL-09 & 0.0 & 0.00 & 0.0 & $0: 00$ & $8: 29$ \\
Average & 271.44 & 2.26 & 11.94 & $10: 29$ & \\
\hline
\end{tabular}

Appendix A shows the operational results of the yard crane equipment operating in the port-container terminal. The average throughput of all yard crane equipment is 355.63 TEUs, and the hourly throughput handled by each container is 2.96 TEUs. The distance traveled from the port-container terminal is $20.07 \mathrm{~km}$, and the average working time is $17 \mathrm{~h}$ and $25 \mathrm{~min}$. The average number of containers reprocessed in the unit site is 39.44 TEUs. Of the 41 yard cranes, only 38 are operational; therefore, three of the yard cranes are not used. The number of containers reprocessed at the unit site is 39.44 TEUs, and this work is mainly handled by cranes 13 to 24 . This indicates that the containers are being reprocessed at the port-container terminal unit where the corresponding yard crane equipment is placed.

Table 5 shows the operational results of the quay crane equipment operating at the virtualized port-container terminal. The average processed container throughput is 3037.13 TEUs, each handling around $12.95 \mathrm{TEUs} / \mathrm{h}$. The working time is $22 \mathrm{~h}$ and $30 \mathrm{~min}$ and the waiting duration is $29 \mathrm{~h}$ and $30 \mathrm{~min}$, indicating that all quay crane equipment are operational. Therefore, there was no idle equipment. Operating equipment costs are also calculated. The government intends to calculate the reduction in operating costs due to the increased operational efficiency of the port-container terminal. The average operating cost per quay crane unit is USD 209,286. The operating cost of the quay crane equipment includes fixed and operating costs.

The correlation between the total container throughput and total operating costs shows that the higher the total container throughput is, the higher the total operating costs are, as shown in Figure 5. However, when handling a certain level of container throughput (2000-3500 TEUs), the total operating costs are constant because the quay crane is large. Unlike the previously presented equipment, ongoing fixed costs are applied continuously.

According to the analysis, only four of the reach stackers are operated without problems. Eight of the nine forklifts, 38 of the 41 yardcranes, and 15 of the quay cranes were found to be handling containers in each port-container terminal smoothly. Therefore, as shown in Table 6, the current relocation of operational equipment can reduce the operating costs of the port-container terminal by USD 13,870,000, with a reduction of USD 146,000 for the forklift, USD 584,000 for the reach stacker and USD 13,140,000 for the yard crane. 
Table 5. Simulation results of virtualized port-container terminal (quay crane).

\begin{tabular}{|c|c|c|c|c|c|}
\hline Division & $\begin{array}{c}\text { Container } \\
\text { Throughput (TEU) }\end{array}$ & $\begin{array}{l}\text { Container Throughput } \\
\text { Per Hour (TEU) }\end{array}$ & $\begin{array}{c}\text { Standby Time } \\
\text { (h) }\end{array}$ & Working Time (h) & $\begin{array}{l}\text { Total Operating } \\
\text { Cost (USD) }\end{array}$ \\
\hline QC-01 & 4760 & 16.98 & $28: 05$ & $35: 01$ & 346,463 \\
\hline QC-03 & 2709 & 14.11 & 29:11 & $22: 48$ & 275,995 \\
\hline QC-04 & 2751 & 12.64 & $29: 34$ & $23: 11$ & 250,848 \\
\hline QC-05 & 2289 & 16.42 & $8: 42$ & $19: 17$ & 230,809 \\
\hline QC-08 & 3019 & 12.10 & $32: 08$ & 21:05 & 176,295 \\
\hline QC-09 & 2508 & 13.21 & $31: 02$ & 21:09 & 159,669 \\
\hline QC-10 & 3493 & 11.12 & $44: 12$ & $23: 20$ & 158,856 \\
\hline QC-11 & 3499 & 11.14 & $44: 12$ & $23: 26$ & 160,844 \\
\hline QC-12 & 2858 & 12.90 & $27: 50$ & $21: 27$ & 158,149 \\
\hline
\end{tabular}

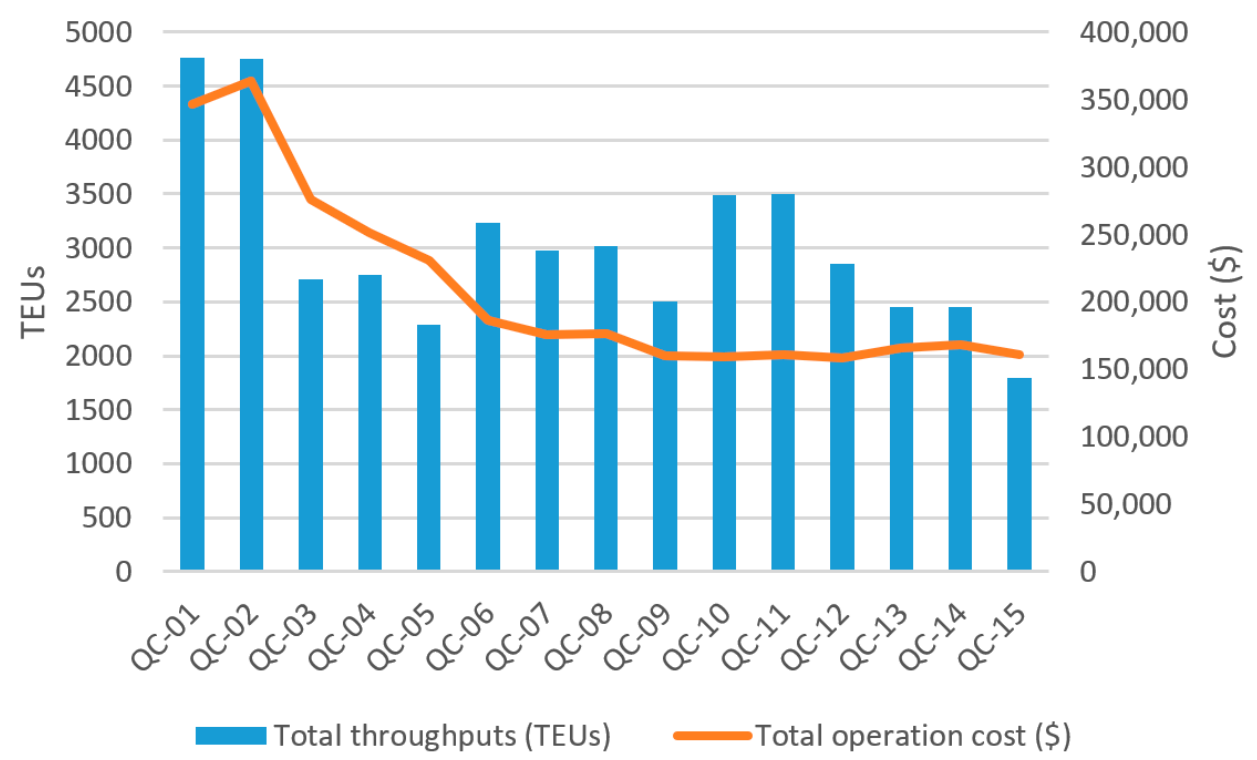

Figure 5. Correlation between container throughput and operating costs (quay crane).

Table 6. Cost of reducing operational equipment for the port-container terminal.

\begin{tabular}{ccccc}
\hline Division & Quay Crane & Forklift & Reach Stacker & Yard Crane \\
\hline Number of reduced devices (unit) & 0 & 1 & 4 & 3 \\
Total work time per unit (h) & 3650 & 3650 & 3650 & 7300 \\
Total fixed cost per time (USD) & 36.5 & 10 & 10 & 100 \\
Total variable cost per time (USD) & 50 & 30 & 30 & 500 \\
Cost reduction per device (USD) & 0 & 146,000 & 146,000 & $4,380,000$ \\
Reduction cost by device (USD) & 0 & 146,000 & 584,000 & $13,140,000$ \\
\hline Total saving cost (USD) & \multicolumn{2}{c}{$13,870,000$} \\
\hline
\end{tabular}

\section{Conclusions}

This study proposes the construction and operation of a virtualized port-container terminal using simulation techniques. The virtual port-container terminal was established using an i-AOMA simulation technique based on operational data from an actual port-container terminal. As operational data processed by existing port-container terminals are applied and used from the cloud, the virtual 
port-container terminal was constructed on the basis of the cloud to link the existing operational data in this study. As a result, a more efficient port-container terminal could be established by reflecting the operational data of Busan's port " $\mathrm{A}$ " container terminal in real time. The operating equipment was simulated for a five-berth port-container terminal operating a quay crane, forklift, reach stacker and yard crane, and the container throughput, container throughput per hour, equipment travel distance, waiting time and working time were calculated. Based on the results, the available capacity of the equipment currently in operation was analyzed, suggesting a reduction of one forklift, four reach stackers and three yard cranes. Further, the port "A" company can save USD 13,870,000 in annual operating costs by reducing the available equipment. Efficient port-container terminal construction and operation is necessary to strengthen the nation's logistics competitiveness. This study emphasizes that, through the continuous analysis and improvement of operations at port-container terminals, more efficient port operations are possible. Moreover, this method allows for the systematic design and operation of new port-container terminals. In future studies, we will implement a simulation model that applies the equipment layout method by considering the failure time of the equipment. We will also add modules that enable real-time data collection and analysis to the i-AOMA model, thus allowing us to analyze a variety of real conditions.

Author Contributions: Conceptualization, G.C.; methodology, G.C.; validation, G.C. and S.-H.L.; formal analysis, G.C.; investigation, G.C.; resources, G.C.; data curation, G.C.; writing—original draft preparation, G.C.; writing-review and editing, G.C. and S.-H.L.; supervision, G.C. All authors have read and agreed to the published version of the manuscript.

Funding: This work was supported by the National Research Foundation of Korea (NRF), funded by the Korean government (MSIP) (grant no. NRF-2018R1D1A1B07044856).

Conflicts of Interest: The authors declare no conflict of interest.

\section{Appendix A}

Table A1. Simulation results for the virtualized port-container terminal (yard crane).

\begin{tabular}{ccccccc}
\hline Division & $\begin{array}{c}\text { Container } \\
\text { Throughput } \\
\text { (TEU) }\end{array}$ & $\begin{array}{c}\text { Container } \\
\text { Throughput Per } \\
\text { Hour (TEU) }\end{array}$ & $\begin{array}{c}\text { Travel } \\
\text { Distance } \\
\mathbf{( k m )}\end{array}$ & $\begin{array}{c}\text { Standby } \\
\text { Time (h) }\end{array}$ & $\begin{array}{c}\text { Working } \\
\text { Time (h) }\end{array}$ & $\begin{array}{c}\text { Re-Handling } \\
\text { Container } \\
\text { (TEU) }\end{array}$ \\
\hline YC-01 & 0.0 & 0.00 & 0.0 & $0: 00$ & $0: 00$ & 0 \\
YC-02 & 0.0 & 0.00 & 0.0 & $0: 00$ & $0: 00$ & 0 \\
YC-03 & 0.0 & 0.00 & 0.0 & $0: 00$ & $0: 00$ & 0 \\
YC-04 & 36.0 & 0.30 & 2.0 & $2: 51$ & $1: 21$ & 0 \\
YC-05 & 67.0 & 0.56 & 4.0 & $5: 13$ & $2: 34$ & 0 \\
YC-06 & 133.0 & 1.11 & 6.8 & $8: 44$ & $5: 03$ & 1 \\
YC-07 & 36.0 & 0.30 & 2.3 & $3: 10$ & $1: 23$ & 0 \\
YC-08 & 69.0 & 0.58 & 3.8 & $5: 41$ & $2: 35$ & 0 \\
YC-09 & 126.0 & 1.05 & 6.6 & $9: 12$ & $4: 41$ & 0 \\
YC-10 & 30.0 & 0.25 & 1.9 & $2: 46$ & $1: 10$ & 0 \\
YC-11 & 65.0 & 0.54 & 4.3 & $5: 56$ & $2: 33$ & 0 \\
YC-12 & 121.0 & 1.01 & 6.6 & $9: 45$ & $4: 34$ & 0 \\
YC-13 & 165.0 & 1.38 & 9.2 & $1: 02$ & $15: 49$ & 121 \\
YC-14 & 199.0 & 1.66 & 11.9 & $1: 59$ & $18: 40$ & 140 \\
YC-15 & 301.0 & 2.51 & 18.1 & $7: 47$ & $22: 53$ & 136 \\
YC-16 & 162.0 & 1.35 & 11.0 & $1: 11$ & $13: 45$ & 97 \\
YC-17 & 203.0 & 1.69 & 12.8 & $2: 03$ & $16: 32$ & 113 \\
YC-18 & 306.0 & 2.55 & 18.5 & $6: 44$ & $22: 09$ & 130 \\
YC-19 & 174.0 & 1.45 & 10.5 & $0: 22$ & $18: 08$ & 167 \\
YC-20 & 199.0 & 1.66 & 11.2 & $0: 47$ & $19: 15$ & 165 \\
YC-21 & 280.0 & 2.33 & 16.4 & $5: 18$ & $23: 24$ & 172 \\
YC-22 & 1545.0 & 12.88 & 92.3 & $3: 01$ & $68: 01$ & 104 \\
YC-23 & 1615.0 & 13.46 & 94.3 & $3: 11$ & $72: 20$ & 127 \\
\hline
\end{tabular}


Table A1. Cont.

\begin{tabular}{ccccccc}
\hline Division & $\begin{array}{c}\text { Container } \\
\text { Throughput } \\
\text { (TEU) }\end{array}$ & $\begin{array}{c}\text { Container } \\
\text { Throughput Per } \\
\text { Hour (TEU) }\end{array}$ & $\begin{array}{c}\text { Travel } \\
\text { Distance } \\
\mathbf{( k m )}\end{array}$ & $\begin{array}{c}\text { Standby } \\
\text { Time (h) }\end{array}$ & $\begin{array}{c}\text { Working } \\
\text { Time (h) }\end{array}$ & $\begin{array}{c}\text { Re-Handling } \\
\text { Container } \\
\text { (TEU) }\end{array}$ \\
\hline YC-24 & 1690.0 & 14.08 & 97.5 & $4: 14$ & $75: 14$ & 133 \\
YC-25 & 84.0 & 0.70 & 5.0 & $6: 12$ & $3: 13$ & 0 \\
YC-26 & 143.0 & 1.19 & 7.4 & $9: 39$ & $5: 22$ & 0 \\
YC-27 & 1950.0 & 16.25 & 101.6 & $6: 50$ & $72: 09$ & 3 \\
YC-28 & 98.0 & 0.82 & 5.3 & $6: 48$ & $4: 01$ & 3 \\
YC-29 & 2004.0 & 16.70 & 105.9 & $9: 25$ & $74: 02$ & 0 \\
YC-30 & 143.0 & 1.19 & 7.7 & $8: 48$ & $5: 25$ & 0 \\
YC-31 & 125.0 & 1.04 & 6.4 & $7: 40$ & $4: 41$ & 0 \\
YC-32 & 132.0 & 1.10 & 7.5 & $8: 38$ & $5: 09$ & 0 \\
YC-33 & 190.0 & 1.58 & 10.6 & $8: 07$ & $7: 15$ & 1 \\
YC-34 & 171.0 & 1.43 & 9.9 & $8: 01$ & $6: 30$ & 0 \\
YC-35 & 117.0 & 0.98 & 6.1 & $7: 59$ & $4: 32$ & 0 \\
YC-36 & 170.0 & 1.42 & 9.7 & $9: 25$ & $6: 28$ & 0 \\
YC-37 & 96.0 & 0.80 & 5.2 & $7: 00$ & $3: 42$ & 0 \\
YC-38 & 163.0 & 1.36 & 9.2 & $8: 41$ & $6: 08$ & 0 \\
YC-39 & 185.0 & 1.54 & 10.6 & $9: 34$ & $7: 15$ & 2 \\
YC-40 & 78.0 & 0.65 & 4.4 & $6: 06$ & $2: 58$ & 0 \\
YC-41 & 143.0 & 1.19 & 8.1 & $9: 32$ & $5: 38$ & 2 \\
\hline Average & 355.63 & 2.96 & 20.07 & $6: 29$ & $17: 25$ & 39.44 \\
\hline
\end{tabular}

\section{References}

1. Yang, H.; Kim, S.Y.; Yim, S. A case study of the Korean government's preparation for the Fourth Industrial Revolution: Public program to support business model innovation. J. Open Innov. Technol. Mark. Complex. 2019, 5, 35. [CrossRef]

2. González, A.R.; González-Cancelas, N.; Serrano, B.M.; Orive, A.C. Preparation of a smart port indicator and calculation of a ranking for the Spanish port system. Logistics 2020, 4, 9. [CrossRef]

3. Kang, H.M.; Hong, S.T.; Moon, S.Y. A study on the efficiency analysis of port automated terminals. Korea Logist. Rev. 2019, 29, 11-22. [CrossRef]

4. Zhao, N.; Liu, Y.; Mi, W.; Shen, Y.; Xia, M. Management of Container Collection Operations in the Container Terminal. In Digital Management of Container Terminal Operations; Springer: Singapore, 2020; pp. 179-232. [CrossRef]

5. Lee, J.H.; Park, N.K. A study on the gap between theoretical and actual ship waiting ratio of container terminals: The case of a terminal in Busan new port. J. Korea Port. Econ. Assoc. 2018, 34, 69-82. [CrossRef]

6. Mourtzis, D. Simulation in the design and operation of manufacturing systems: State of the art and new trends. Int. J. Prod. Res. 2020, 58, 1927-1949. [CrossRef]

7. Gulia, P.; Khari, M.; Patel, S. Metrics analysis in object oriented and aspect oriented programming. Recent Pat. Eng. 2019, 12, 117-122. [CrossRef]

8. Hsu, H.P.; Wang, C.N.; Chou, C.C.; Lee, Y.; Wen, Y.F. Modeling and solving the three seaside operational problems using an object-oriented and timed predicate/transition net. Appl. Sci. 2017, 7, 218. [CrossRef]

9. Choi, H.R.; Kim, D.H.; Cho, M.J.; Lee, K. The fourth industrial revolution and the countermeasures of the marine port logistics industry. J. Korean Inst. Commun. Inf. Sci. 2018, 43, 1540-1549. [CrossRef]

10. Kwang, Y.J.; Kim, J.B. Web monitoring system for cloud desktop virtualization OS. Asia Pac. J. Multimed. Serv. Converg. Art Humanit. Sociol. 2017, 7, 847-855. [CrossRef]

11. Park, B.K.; Park, M.S. Real-Time port logistics location tracking system using IP-RFID. J. Korea Inst. Inf. Commun. Eng. 2018, 22, 1531-1537. [CrossRef]

12. You, J.W.; Kim, Y.S. A Study on the perception of the subjects about automated container terminal. J. Navig. Port. Res. 2020, 44, 195-202. [CrossRef]

13. Saorín, J.L.; de la Torre-Cantero, J.; MeliánDíaz, D.; López-Chao, V. Cloud-Based collaborative 3D modeling to train engineers for the industry 4.0. Appl. Sci. 2019, 9, 4559. [CrossRef] 
14. Cho, G. Study on establishment of smart logistics center based on logistics 4.0. J. Multimed. Inf. Syst. 2018, 5, 265-272. [CrossRef]

15. Kim, S.W. Flexible crypto system for IoT and cloud service. J. Korea Inst. Inf. Electron. Commun. Tech. 2016, 9, 15-23. [CrossRef]

16. ISL Applications. CHESSCON Simulation User Manual. 2013. Available online: www.chesscon.com (accessed on 16 June 2020). 